This is the post_peer review, pre-publication version of the following article:

Holloway, J.V., Rillig, M.C., Gurnell, A.M. 2016. Underground riparian wood: Buried stem and coarse root structures of Black Poplar (Populus nigra L.). Geomorphology, (2016),

http://dx.doi.org/10.1016/i.geomorph.2016.08.002

The published version is obtainable from http://dx.doi.org/10.1016/j.geomorph.2016.08.002

0169-555X/@ 2016 Elsevier B.V. All rights reserved.

\title{
Underground riparian wood: Buried stem and coarse root structures of Black Poplar (Populus nigra L.)
}

\author{
James V. Holloway ${ }^{1}$, Matthias C. Rilligi, ${ }^{2,3}$, Angela M. Gurnell1 \\ 1 Queen Mary University of London, School of Geography, Mile End Road, London E1 4NS, \\ United Kingdom \\ 2 Freie Universität Berlin, Institut für Biologie, Plant Ecology, Altensteinstr. 6, Berlin D-14195, \\ Germany \\ 3 Berlin-Brandenburg Institute of Advanced Biodiversity Research (BBIB), Berlin D-14195, \\ Germany
}

\begin{abstract}
Despite the potential importance of tree species in influencing the processes of wood recruitment, transport, retention, and decay that control river wood budgets, focus has been relatively limited on this theme within fluvial wood research. Furthermore, one of the least investigated topics is the belowground living wood component of riparian trees.

This paper presents observations of the morphology and age of buried stem and coarse root structures of eight Populus nigra individuals located in the riparian woodland of two sites on the middle to lower Tagliamento River, Italy. This species was selected because of its wide distribution along European rivers and its frequent dominance of riparian woodland.

Each tree was excavated by hand to expose a minimum of half of the root system with complete exposure of the main axis. Smaller roots were then removed and larger protruding roots cut back to permit access to the main axis. The excavated structures were photographed from multiple angles for photogrammetric modelling; the structure and character of the exposed sediments around the tree's main axis were recorded; and wood samples were taken from the main aboveground stem(s), sections of the main buried axis, and major roots for dendrochronological analysis. Results from these field observations and laboratory dating of the wood samples were combined to describe the belowground morphology of each tree and to draw inferences concerning the impact of fluvial disturbances.

Common features of these excavated structures included: (i) rooting depths to below the bar surface where the original tree established, with many young roots also existing at depth; (ii) translocation of the main buried axis in a downstream direction; (iii) a main buried axis comprised mainly of stems that have become buried and then generated new shoots, including multistem patches, and
\end{abstract}


adventitious roots; (iv) the presence of steps and bends in the main buried axis associated with the generation of coarse lateral roots, that reflect the sedimentary structure of the surrounding aggraded bank sediments; and (v) grafting of roots within and between some sampled trees.

Overall, the sampled trees possessed extremely complex three-dimensional buried wood structures that permeate bank sediments and tie the tree and aggraded bank sediments to basal gravels. These properties and the considerable amount of underground wood that is present have great significance for anchoring trees and giving uprooted trees and root wads a propensity to snag once they enter the fluvial system. Furthermore, the ability of this underground biomass to sprout suggests that uprooted and remaining components of root networks following tree uprooting may sprout, generating new vegetation canopies that can trap mobile wood. Overall, this underground wood offers many traits that may tighten wood budgets, and it is likely that other riparian Salicaceae species with similar traits may have similar wood budget impacts.

Keywords: Populus nigra; underground wood; buried stems; adventitious roots; root system architecture; structure-from-motion

\section{Introduction}

To date, most fluvial wood research has focused on the characteristics of large wood pieces and accumulations retained within river systems and set in the context of large wood dynamics and budgets at catchment to reach scales (Benda and Sias, 2003; Wohl, 2013; Ruiz-Villanueva et al., 2016). Despite the potentially enormous importance of tree species in influencing all of these processes, there has been a more limited focus on how species may influence the processes of wood recruitment, transport, retention, and decay that control river wood budgets (Gurnell, 2003, 2012). Nevertheless, since 2000, researchers have started to look in more detail at the characteristics of the trees from which large wood is recruited (Wohl, 2013; Ruiz-Villanueva et al., 2016), and the fundamental importance of species for fluvial wood properties and dynamics is becoming increasingly clear. For example, a 'large wood cycle' dominated by large, slow-decaying coniferous species, has been proposed (Collins et al., 2012). This concept, based on observations in the Pacific Northwest of the USA, emphasises the crucial importance of large, slow-decaying wood pieces that accumulate into jams that eventually form hard points within the alluvial deposits of the floodplain. Seedlings germinate and grow to maturity on these stable hard points, eventually providing further very large wood pieces to the fluvial system. Thus the age structure and rates of turnover of the riparian forest are strongly controlled by buried wood hard points. Furthermore, although most research has focussed on dead pieces of large wood, research concerning riparian tree species that are able to sprout following uprooting, transport, and deposition has also demonstrated the crucial importance of the species of riparian tree delivering wood to the fluvial system (Gurnell, 2013, 2016). This latter research has demonstrated how such species can act as river physical ecosystem engineers by forming vigorous vegetated patches from deposited 'living' wood that are anchored to river bar surfaces by their root systems. These patches grow rapidly, forming a further type of hard point that strongly influences the extent and turnover of riparian woodland and thus the recruitment of wood (Zanoni et al., 2008) and also the morphology of the entire active river channel 
(Bertoldi et al., 2011). Moreover, such resprouting species frequently dominate the riparian tree communities of temperate river systems (Karrenberg et al., 2002).

Since 2000 , a rapidly increasing body of international research has indicated the importance of tree species in determining wood behaviour. This research has investigated key tree properties for river wood dynamics, including the density and decay resistance of the large wood produced by different tree species (e.g., Bilby, 2003; Tabacchi and Planty-Tabacchi, 2003; Scherer, 2004; Mäkipää and Linkosalo, 2011; Ruiz-Villanueva et al., 2014; Lawson et al., 2015); aboveground tree architecture, flow resistance, strength, and biomass (e.g., Baptist et al., 2007; Aberle and Järvelä, 2013; Bendix and Stella, 2013; Camporeale et al., 2013; Jalonen and Järvelä, 2014); and the ability of trees and wood to interact with sediment erosion, deposition, and retention processes (e.g., Gurnell et al., 2001, 2008; PollenBankhead and Simon, 2010; Manners et al., 2015), but much remains to be investigated.

One of the least investigated topics is the belowground component of riparian trees. While research on buried dead wood is scarce, research on the impact of buried living wood on the large wood cycle is particularly limited. In general, root systems provide anchorage for a tree and ensure water and nutrient supply. Rooting depth, density, size, and strength all contribute to tree anchorage and resistance to uprooting (Burylo et al., 2009) and so are all relevant to the wood cycle. Early successional species (e.g., pioneer riparian species) tend to have a significantly greater proportion of roots at depth than late successional species (Gale and Grigal, 1987), and species adapted to dry climates generally have deeper root systems than those adapted to moister conditions (Brunner et al., 2015). Furthermore, the root systems of woody plants comprise a wide range of different root sizes: coarse roots provide perennial structures that anchor trees, transport water and nutrients, and store nutrients and carbohydrates; fine roots are more ephemeral and forage for resources (Comas et al., 2013). Root properties vary between and within species, particularly in relation to tree age and physical, chemical, and biological environmental conditions (Brassard et al., 2009; Pasquale et al., 2012; Bardgett et al., 2014).

Despite such general knowledge regarding tree root systems, little is known about rooting depth, strength, and architecture among riparian tree species or how these vary under different environmental conditions, although root strength has been shown to vary with root diameter as well as between species (Simon and Collison, 2002; Pollen et al., 2004; Pollen-Bankhead and Simon, 2010). These properties strongly affect the ability of trees to avoid uprooting and to reinforce sediments (e.g., Docker and Hubble, 2008) and thus to influence the wood cycle.

This paper focuses on one species of riparian Salicaceae. The Salicaceae dominate riparian woodland across the northern temperate zone (Karrenberg et al., 2002). These poplar and willow species are typified by high growth rates and the ability to propagate from vegetative fragments, even when these are very small. These characteristics appear to have evolved in response to the particular selection pressures experienced in riparian zones (Eckenwalder, 1996). The high root growth rate of seedlings permits establishment on newly deposited fluvial sediments with rapidly declining water tables (Mahoney and Rood, 1992; Barsoum and Hughes, 1998; Guilloy-Froget et al., 2002); high stem elongation rates in established plants confer tolerance to burial by flood-deposited sediment; and the propensity for vegetative reproduction from fragments permits survival of destructive flow events 
(Barsoum et al., 2004). Furthermore, these species often produce vast networks of adventitious roots that give rise to new stems by suckering. Consequently, natural riparian stands of these species usually consist of genetically uniform patches of clonal stems, often with a large, shared root network. This vast underground biomass, which is particularly significant in younger trees (Shepperd and Smith, 1993), constitutes a large store of readily mobilised carbohydrate (Nguyen et al., 1990; Pregitzer and Friend, 1996) that can support replacement of stems destroyed by major disturbances as well as rapid colonisation of newly deposited fine sediments and the exploitation of their nutrient and moisture storage resources.

The species on which we focus is Populus nigra L., a tree that often dominates the riparian margins of European rivers and whose role as a river physical ecosystem engineer has been recently reviewed (Corenblit et al., 2014). Corenblit et al. (2014) considered the performance of this species through the four phases of the fluvial biogeomorphic succession (Corenblit et al., 2007), highlighting (among other things) the way in which its root systems may develop with tree age according to environmental factors such as moisture availability and sediment retention. However, remarkably little is known about the depth, longevity, and growth of buried stems and associated roots of this species, which have such major implications for landform stability and turnover. Its role in driving vegetation and landform development along river margins dictates that it naturally grows in a highly disturbed environment where floods and associated erosion and deposition of sediment are common events. Thus we can assume that its belowground complexes of buried stems and roots not only resist such processes but also respond to them. As part of a larger study of the character and controls on the root systems of Populus nigra, in this paper we investigate the morphology and age of the main buried axis and largest roots of eight case study trees and their sedimentary environment within two reaches of the braided, gravel-bed Tagliamento River in northeast Italy. The aim of this research is to highlight the characteristics of this underground large wood component of Populus nigra, which is a source of large quantities of wood to the Tagliamento River (e.g., Gurnell et al., 2001, 2005), and is crucial to the trees' ability to resist displacement in erosive flood events. We also infer the history of the formation of this underground large wood component from this morphological and dendrochronological information. A complementary process history, constructed from historical sources including flow records and aerial imagery, is presented in Holloway et al. (2016), which confirms or develops the interpretations presented in this paper, which are based entirely on the characteristics of the underground roots and their sedimentary environment.

\section{Study area}

The Tagliamento River is located in northeast Italy where its main stem rises in the southern fringe of the European Alps and flows $\sim 170 \mathrm{~km}$ to the Adriatic Sea. The river spans a climatic gradient from alpine in its headwaters to moist Mediterranean in its middle to lower reaches. Floods can occur at any time of year but are most frequent in spring and autumn. The main stem of the Tagliamento is bordered by riparian woodland along almost its entire length, with distinct downstream changes in dominant tree species. Alnus incana and Salix eleagnos dominate the headwaters, whereas Populus nigra dominates the middle and lower reaches (Karrenberg et al., 2003). This paper focuses on two sites in the middle 
to lower reaches of the Tagliamento River. A 'northern site', located between river kilometres 72 and 80 , and a 'southern site', located between river kilometres 113 and 116. These two sites were chosen because we anticipated higher moisture availability at the northern than the southern site, reflecting broad trends in groundwater levels along the middle to lower reaches of the river. Although all studied trees were located sufficiently close to the banks of islands or the main channel to make excavation feasible, at each site we selected trees from different locations that appeared to represent different degrees of exposure to river flows. In this way, we attempted to sample a broad range of environmental conditions.

\section{Methods}

\subsection{Field sampling and field and laboratory measurements}

The root systems of eight mature Populus nigra individuals situated close to eroding banks of the Tagliamento River were investigated. Three trees were studied during July and August 2014 and five trees during March 2015. The trees were located within two different sites and at different locations within each site to ensure coverage of a range of environmental conditions. Twenty candidate trees were identified in initial walk-over surveys, according to their ease and safety of access for excavation and the representative form of their canopy in relation to trees in the surrounding area of riparian woodland. At the time of the walk-over, each tree was sufficiently close to the edge of a recently eroding island or floodplain margin for hand excavation and sampling of its root system to be feasible within two to three days, but sufficiently far from the eroding edge for the tree's coarse root structure to be well preserved. From these twenty trees, eight were finally selected for excavation and detailed analysis, four in the northern and four in the southern site (Table 1). Unfortunately, the near-fully excavated root system of one tree in the northern site was buried and the tree was destabilised when sediment was deposited around it by a flood before it was fully sampled. Therefore, only seven trees could be fully investigated, but the information available for the eighth tree is also presented.

The following four groups of measurements were conducted at each tree:

First, the location (latitude, longitude) of each tree was determined using a hand-held GPS (Garmin GPSmap 62s) and then the dimensions of the tree were measured. Tree main stem length (i.e., height, but accounting for any lean) was measured to $\pm 0.25 \mathrm{~m}$ using a Suunto PM5-1520 clinometer, and tree main stem diameter at $1.2 \mathrm{~m}$ above the ground surface was measured to $\pm 1 \mathrm{~cm}$ using a measuring tape.

Second, each tree was then secured to nearby trees using ropes and its root system was excavated by hand (Fig. 1A) to expose a minimum of half of the root system with complete exposure of the main axis (Fig. 1B). Small roots ( $<2 \mathrm{~mm}$ diameter) were entirely removed, and larger protruding roots were cut back to permit access to the main axis. The excavated structures were then photographed from multiple angles for photogrammetric modelling (mean 217 JPEG images (16 MP) per tree; Nikon D7000; 18-200 mm Nikkor set at $18 \mathrm{~mm}$; ISO-500; variable aperture and shutter).

Third, the structure and character of the exposed sediments around the tree's main axis were recorded. The depth (to nearest $0.5 \mathrm{~cm}$ ) and broad sediment calibre (dominance of one or more of the 
following sediment size classes: silt-clay, sand, gravel, pebbles) within the exposed sediments around the main axis were visually assessed and recorded.

Fourth, wood samples were taken for dendrochronological analysis. Such techniques have long been used in the study of landforms and fluvial processes (see Osterkamp et al., 2012; Stotts et al., 2014). In the present research, the main aboveground stem(s) of each tree was cored at $1.2 \mathrm{~m}$ from the ground surface and all of the main sections of the larger diameter buried axes of each tree were cored using a $5.15 \mathrm{~mm}$ increment borer (Haglöf, Sweden). In addition, sections of $\sim 1 \mathrm{~cm}$ length were cut from smaller roots of interest. Upon extraction, tree cores were placed in paper straws for transport back to the laboratory. Here they were oven dried $\left(105^{\circ} \mathrm{C}\right)$ overnight and then fixed with PVA adhesive to wooden mounts for surface preparation. The wood sections were also dried overnight at $105^{\circ} \mathrm{C}$. Both types of samples were then sanded with increasingly fine sandpaper up to 400 grit. The final surface of each sample was finished with furniture polish and rings were inspected using a hand lens with 10x magnification. Upon burial, annual growth rings often become indistinct (see, e.g., Friedman et al., 2005), and this phenomenon was encountered in the sampled roots. In consideration of this, together with errors associated with sample collection and preservation, ages estimated from wood cores and sections represent minima, and thus wood structures must have established on or before any dates reported.

\subsection{Data analysis}

The geometry of buried root structures was recorded by creating three-dimensional models using a Structure from Motion (SfM) photogrammetry interface (Agisoft PhotoScan 1.1.6). This allows a set of photographs taken from different directions to be integrated into a model that can be rotated and inspected in detail to reveal three-dimensional features that may not be obvious from the original photographs. The method was initially trialled with root systems where finer roots were not trimmed, but the point-matching algorithm was not able to run successfully in these cases. Therefore, the root trimming conducted in the field and described in the previous section was crucial to developing a threedimensional model of the main axis and larger roots for detailed investigation.

\section{Results}

The measured properties of the eight studied trees (Table 1) revealed tree ages in the range of 12 to 20 years, stem diameters from 12 to $23 \mathrm{~cm}$, stem lengths from 11 to $17 \mathrm{~m}$, giving average stem vertical growth rates of 0.7 to $1.1 \mathrm{~m} \cdot \mathrm{y}^{-1}$ and average stem radial growth rates (at $1.2 \mathrm{~m}$ ) of 3.4 to 5.7 mm. $y^{-1}$. These estimated vertical growth rates indicate that if cores had been taken at the ground surface, annual growth rings would have indicated tree ages of 0 to +1 years in comparison with the age determined at $1.2 \mathrm{~m}$ above the surface. Several of the studied trees had a closely associated pair of stems. In these cases, the summary information presented in Table 1 relates to the larger stem.

The types of information captured for each tree are illustrated in Fig. 2 using data for tree S1. Images of all trees are presented so that the upstream direction is on the left of the image and downstream on the right (and thus in some cases they are presented as mirror images). Each image presents the SfM model of the base of the aboveground stem and coarse root system (with its axis 
projected horizontally and parallel to the upstream-downstream direction), apart from tree N4 where photographs are used to illustrate its part-excavated characteristics. The SfM image or (photograph for N4) is then annotated in three ways. First, key features of the above- and belowground stem-root axes of the tree are identified along with the vertical layered structure of the sediments around the main belowground axis (Fig. 2, S1). The panel on the right of these images indicates the dominant sediment calibre class(es) in the main strata close to the tree's main axis. Second, estimates of the latest dates of origin of parts of the main axis are shown (Fig. 2, S1A), and lastly estimates of the latest dates of origin of the main lateral roots are provided (Fig. 2, S1B).

The key stem-root and sedimentary features for the four trees in the northern site and the remaining three trees in the southern site are presented in Figs. 3 (trees N1-N3), 5 (N4), and 6 (S2 to S4), respectively. The estimates of the latest dates of origin of the main root axis and main lateral roots are provided for the four trees in the northern site and the remaining three trees in the southern site in Figs. 4 (trees N1-N3), 5 (N4), and 7 (S2 to S4), respectively. For clarity and to avoid repetition, the detailed inferences drawn from the morphology and dating are now combined with descriptions of the data gathered in relation to each tree in this Results section. Table 2 summarises some characteristics of the studied trees, which arise from the interpreted results for each individual and provide the foundation for the Discussion section.

\subsection{Tree $N 1$}

This single-stemmed tree (Fig. 3, N1) has a main root axis composed of three parts: a nearvertical upright, large diameter section at $\mathrm{A}$ with horizontally radiating laterals; a slightly curved section with few laterals at B, pointing downstream; and a straight section lying at $\sim 30^{\circ}$ to horizontal at $\mathrm{C}$. A proliferation of lateral roots emerges from the junction of sections $B$ and $C$, and a subsidiary stem $D$ originating from the distal end of section $\mathrm{C}$, which had died and no longer emerged at ground level at the time of excavation. One particularly large lateral root $E$ is also noteworthy. The cavity below the junction of $A$ and $E$ was caused by loss of unconsolidated gravels during excavation. In general the sediments around the main axis are sand and finer with gravels only at the lowest elevations, except for a layer coincident with section $\mathrm{B}$, which also included organic material.

The latest possible dates of origin of various parts of the root system (Fig. 4, N1A) and lateral roots and subsidiary stem (Fig. 4, N1B) suggest that the oldest part of this system, corresponding with the coarse gravel-cobble layer (a buried bar surface?), established in or before 1994 (date associated with the base of the main axis, the stem at $1.2 \mathrm{~m}$ from the ground surface, and the lower part of the subsidiary stem). The large lateral root $\mathrm{E}$ dates to 1998 or earlier and corresponds with the upper limit of gravel within the profile. The presence of two, connected, downstream-deflected sections of the main axis and two distinct gravel deposits suggests that this tree's coarse root system was affected by two significant floods. The extant components appear to have originated near the lower limits of the excavation (just above the water table at the time of sampling) and the main axes appear to be buried stems rather than taproots. The length and shape of the lower deflected section suggest that the sapling was at least $1 \mathrm{~m}$ tall and quite inflexible at the time of the first flood. Lateral buds or existing small branches near the newly deposited gravel ground surface became the dominant vertical stems, two of 
which survived to the time of excavation, and the date of this event appears to be 1996 or earlier. A second disturbance event again caused a deflection and burial of the two surviving stems. The limited accumulation of fine sediments beneath the second gravel layer and the fact that the new stems must still have been sufficiently flexible to result in the curved form of the main axis, suggest that this second event occurred soon after the first, and from the wood dates, probably occurred in or before 1998. Following these disturbances, deep and upwardly fining sediment deposited around the main axis is consistent with gradual surface aggradation around the growing vegetation.

\subsection{Tree $\mathrm{N} 2$}

This single-stemmed tree (Fig. 3, N2) has a single main root axis with large lateral roots at A, $\sim 10 \mathrm{~cm}$ below the ground surface. One of these shallow laterals has branched at $B$ to exploit deeper layers of the thick fine sediment deposits. Lateral roots are relatively evenly distributed along the main axis, although they increase slightly in frequency just below a sand layer at $C$. The main axis leans gently downstream with a slight increase between $C$ and $D$. Sediments are predominantly of sand and finer calibre apart from a gravel layer located at the level of the water table at the time of excavation, into which the bottom of the principal axis is rooted.

The main stem (Fig. 4, N2A) dates to before 1992 and, although the cores were difficult to read, this appears to apply to the whole main axis (the lowest sample pre-dates 1994). Lower lateral roots (Fig. 4, N2B) developed before 2003 (one before 1995), whereas the upper laterals are younger. The simple main axis form, well-distributed lateral roots, and predominantly sand and finer sediments indicate gradual burial since the tree originally germinated or sprouted from deposited wood in association with a gravel layer (bar surface?). However, the downstream lean of the main axis, particularly in its lower half, suggests some early flood disturbance, which, based on the age of the main stem (pre-1992), base of the main axis (pre-1994), and deep lateral roots (pre-1995), probably occurred in the early 1990s. Furthermore, the younger laterals from the upper near-vertical main axis, suggest negligible physical flood disturbance of the tree but progressive surface aggradation from at least 2002.

\subsection{Tree $\mathrm{N} 3$}

This single-stemmed tree (Fig. 3, N3) displays a small second stem A, aligned with the upper tilted section of the buried axis ( $D$ to $F$ ). In addition, $E$ (long dead) may represent an extension of the buried main axis between $C$ and $D$. The entire main axis is curved and attached to a branching mass of dead wood at B. A piece of nylon cord was found tied around the main axis where the living and dead wood join (just upstream of $\mathrm{C}$ ), and the lower extremity of the living part of the axis has a proliferation of roots emerging from its lower side at $C$ and extending up- and downstream and into the only gravel layer exposed at the base of the excavation. A second area with many large adventitious roots is located just above where the main axis starts to slope more steeply upward at D. Most of the roots are on the lower, downstream-facing side of the main axis and extend into two layers of sand and finer material separated by predominantly loose sand. Where the main axis becomes vertical at $F$, a collar of lateral roots was observed in the field, a large one of which is visible pointing upstream. 
The main axis (Fig. 4, N3A) dates back to at least 2001, with the aerial portion of the stem perhaps being one to two years younger. The small subsidiary aerial stem dates to 2001 and most of the lowest laterals appeared to have originated around 2002, while the shallower lateral roots date to 2005 and 2009. This evidence suggests that the buried main axis was the apical part of a larger young tree, upright before 2001, which was probably eroded and deposited at this site. The gently upwardcurving form of the main axis suggests gradual deflection and burial by successive inundation events keeping pace with phototropic apical growth. Each time the apex of the main stem started to shoot upward, it appears to have been deflected downstream and buried deeper in sand and fine sediment.

The main axis can also be considered in two sections ( $C$ to $D$ and $D$ to $F$ ). The long, upstreampointing lateral root parallel with the bank top (Fig. 4, N3B) suggests that most sediment deposition occurred before 2005, and A and E appear to be remnants of original apical shoots, suggesting initial deposition of the 'parent' tree occurred before 2001, at which point a lateral bud from node $D$ became the dominant shoot (of which $A$ is a remnant). A second flood (prior to 2005) then buried and imposed a second deflection on the main axis and the extant main aerial stem sprouted from node $F$. The nylon cord tied round the main axis just below node $\mathrm{C}$ probably led to the mortality of the lower portion of the system (around 2006/7, judging by changes in wood properties in the surviving lower lateral roots at that time).

\subsection{Tree $\mathrm{N} 4$}

This single-stemmed tree (Fig. 5, N4) was destabilised and reburied when only partly excavated, and so the information gathered is incomplete. Just below the base of the main stem, the main buried axis is initially almost horizontal, lying on top of or just within a narrow band of fine sediment immediately above a sand-gravel-pebble layer (A-B). Many lateral roots of considerable size emerge from a node on the main axis at $A$. Below this near-horizontal section is a portion of the main axis with a downstream lean of around $35^{\circ}$ from the vertical (B-C), defined at its base by another node with prolific lateral roots $(C)$ emerging into a second narrow fine sediment layer above a deep layer of mixed sandgravel-pebble-cobble material. Many of these horizontal adventitious roots are weakly grafted to each other. Below the upper near-horizontal portion of the main axis are at least two stout, near vertical roots ( $D$ and $E$ ). Below the second fine sediment layer, the main axis takes a wandering, near-vertical course through gravel layers $(F)$ beyond the limits of excavation, with one notable lateral $(G)$ also following a wandering near-vertical course. A limited and incomplete set of wood samples were obtained from this tree (Fig. 5, N4a and N4b), with the oldest (1999, lower set of laterals, Fig. 5, below B) setting a limiting date on its origin, and the main stem at $1.2 \mathrm{~m}$ dating back to 2001. The main buried axis was established before 2001, and the upper set of laterals by 2003 .

\subsection{Tree S1}

Above ground (Fig. 2, S1), this tree has two relatively large stems, which are attached at $\mathrm{C}$ to a single, though complex, main buried axis that is $\sim 3.5 \mathrm{~m}$ in length and steeply inclined in a downstream direction. The main axis originates from a deep layer of silt and clay, overlying a mixed coarser layer, at $D$, from which horizontal roots spread in all directions. Many large, downstream-oriented adventitious 
roots emanate from another major node at $E$ and are deflected and contorted at $F$, where they are underlain by a patch of silt and clay (Fig. 2, S1, outlined with a dashed gold line). Thereafter, the main axis is virtually uninterrupted by adventitious roots until a third major node at $\mathrm{G}$, where a thick lateral branch takes a $45^{\circ}$ course up to $C$. This branch thereafter becomes the dominant buried axis, although two large roots continue along the line of the original axis. Long lateral roots also extend in all directions in the finer surface sediments from node $C$.

Sections of the buried structures date the origin of the tree to before 1993. There is no clear pattern in the dates for the main axis (Fig. 2, S1A), but the extant aerial stems appear to be younger (predating 1998). At least two of the lateral roots (Fig. 2, S1B) in an upper gravel layer are relatively old (1994 or earlier), whereas other adventitious roots date to between 1996 and 2008.

The complex form, age structure, and sediment profile (mainly gravel-sand with many silt-clay layers) of this tree suggest a complex history. The original young tree appears to have been flattened in a flood during or before 1993, creating the lowermost curve in the main axis ( $D$ to $E$ ) and potentially retaining fine sediments in its flattened canopy to produce the patch of silt and clay outlined with a gold dashed line (Fig. 2, top). At this point, node E sprouted a shoot that became the dominant axis. Scars in the growth rings suggest that the next major disturbance event was 1996, bending the tree almost flat once again. Much of the canopy appears to have survived this event, with the apical stem and a lateral branch probably giving rise to the axes G-H and G-C, respectively. Within this buried canopy, the uppermost node $C$ sprouted new shoots, and at the same time, many of the long adventitious roots emerged from the deeper node $\mathrm{E}$. The severe distortion of these adventitious roots at point $\mathrm{F}$ suggest their partial exposure and reburial, possibly in the late 1990s.

\subsection{Tree $S 2$}

Three stems (A, B, C) emerge at the ground surface (Fig. 6, S2), although stem C was dead at the time of excavation. It was not possible to determine whether the living stems $A$ and $B$ had grafted near the soil surface, but they are intimately associated. From the surface, the main stems all penetrate through an upper sand deposit, a sand-gravel-pebble layer, a layer of loose pebbles, and finally a mixed silt-sand-gravel-pebble layer. These are underlain by a sand-gravel-pebble layer that is penetrated by the deepest roots. Many shoots emerged in the past from the base of stem B but were dead when excavated. Stem B also has large, downstream-leading lateral roots in the deeper and near-surface sand and finer-sediment-dominated layers. Stems $C$ and $A$ both originate from node $D$, from which roots also sprout. Node $D$ is connected to a deeper node $E$ with a complex, wandering and far-reaching root system. Stem B originates from an entirely separate structure at $F$, which possesses many large horizontal, downstream-pointing roots, emerging from a short section of large diameter horizontal stem. The lower parts of the main buried axes (in the upper gravel layer) are deflected downstream and into the bank, while the upper sections (in a sand layer) are deflected only in the downstream direction.

The two aerial stems (Fig. 7, S2A) were established before 2000; and the buried axes, a year earlier, with the lowest parts dating back before 1995. Lateral roots (Fig. 7, S2B) are generally more recent, although the estimated ages relating to stem $C$, which was dead when sampled, are probably underestimates. Similarly to Tree N1, the parallel stems may be attributed to sprouting from multiple 
nodes of an early, near-flattened straight stem on the alignment $E-F$, the connecting parts of which have since decayed, resulting in two separate structures at this depth. Although dating is difficult, it appears that these newly sprouted parallel stem axes were disturbed by one or more events when they were young and flexible (giving rise to their curving form), probably in the late 1990s.

\subsection{Tree $\mathrm{S} 3$}

This tree (Fig. 6, S3) was part of a patch of approximately five stems of similar size and two further sizeable dead stems. The excavated stem has several large laterals just below the ground surface at $A$, below which there is a metre-long vertical section with intermittent adventitious roots. Below this, a large diameter, near-horizontal, and upstream-pointing section is present at node $B$, which also has remnant stubs of several other horizontal roots and two stems, pointing back into the bank, coincident with the top of a sand-gravel-pebble layer. A short distance upstream on this dominant horizontal axis, at $C$, is a junction with a major downstream-pointing horizontal root, $D$, and a short distance $(\sim 20 \mathrm{~cm})$ farther along the upstream-pointing axis at E, are several strong grafts (Fig. 8) with roots emerging from the bank and apparently connected to other stems in the tree cluster. Below $E$, the main axis penetrates thick sand-gravel-pebble deposits in a wandering but more-or-less vertical course, with significant laterals in the surface of the gravel at point $F$ and coincident with a deeper silt inclusion at $\mathrm{G}$. The root system extends below the limits of excavation at $\mathrm{H}$.

The aerial stem dates back to at least 2001 (Fig. 7, S3A) and the buried portion of its vertical axis has a similar date. However, below node B, the main axis pre-dates 1998. Lateral roots (Fig. 7, S3B) are of varied ages, with one of the uppermost established by 2003 , and most of the horizontal roots associated with the grafting layer (i.e., C, D, E) originating in or before 1999. The fact that roots have very readily grafted suggests that the stems adjacent to the studied tree are all the same clone. The sinuous course of the main axis below point $B$ suggests it is a sinker root, while the straight but downstream deflected axis above suggests it is a stem, which was flattened and buried before 1998, with a proliferation of adventitious roots expanding in 1999 into surrounding sand and finer sediments. Other parts of the clonal root system appear to have expanded horizontally at this time, grafting where their paths crossed. The most recent major phase of deposition appears to have occurred around 2000 , and the major vertical axis seems to be a sucker which has grown up through an aggrading silt-sand layer. The second highest lateral root dates the upper limit of this layer to 2001, whereas the sand layer above, dated by the highest labelled lateral root, was deposited before 2003.

This root system shows the markedly different behaviour of a clonal, suckering, well-developed planar root network, in contrast to structures related to the early developmental phases of singledeposited trees, fragments, or seedlings, found in the preceding examples, which may later produce such expansive horizontal networks.

\subsection{Tree S4}

This tree has two stems (Fig. 6, S4), the smaller of which was excavated, being closer to the eroding bank. This stem has many laterals just below the ground surface, supporting the upstream lean of the stem. The two stems are connected by a sizeable $(\sim 20 \mathrm{~cm}$ diameter) buried trunk at $A$, which 
takes a straight, gently-inclined course from the larger to the smaller stem, turning more steeply downward to connect at B. One other small, dead, stem emerges from this connecting section at $\mathrm{C}$. Node B, associated with the top of the gravel layers, also possesses many large horizontal roots projecting downstream. Below this, the very large diameter main axis is inclined at an angle of about $20^{\circ}$ from horizontal for $\sim 35 \mathrm{~cm}$, with a substantial root emerging at $D$ and extending downstream along the top of an unconsolidated sand-gravel-pebble layer. Below this, the main axis is vertical, with another major node at $E$ from which four large horizontal roots spread in all directions, following the same horizon as $D$. The bottom of this vertical section of the main axis is marked by a near $90^{\circ}$ bend at $F$ from which it tracks outward toward the foreground of the image.

The deepest and oldest parts of this system were established in 1994 (Fig. 7, S4A), while the two aerial stems date back to at least 1997. The large connecting axis also pre-dates 1998. Lateral roots (Fig. 7, S4B) in the upper sand layers pre-date 2002, while lower laterals date to the mid-to-late 1990s.

The dated sections suggest recruitment before 1994. The main axis below node $E$ has irregularly shaped annual rings throughout, indicating that this originated as a root, contorted as it penetrated gravel, and that node $E$ is the point of origin of this tree. This is also suggested by the regularly distributed lateral roots tracking out in all directions from this point. Below this point the taproot turns through $90^{\circ}$ where it encounters a more consolidated layer in the sand-gravel-pebble deposit. The 1996 date of the large root D suggests that this was when the original shoot was flattened by a flood. A new shoot from node $B$ then presumably became the dominant stem, only to be knocked down toward the bank, probably later in the same year. The sharp angle of the deflected stem also suggests that it was probably very young and flexible at this time. Following 1996, the deflected axis seems to have sprouted a strong distal shoot (the larger, more downstream of the two trunks standing at the time of excavation), a shoot immediately at its base at B (the second trunk standing at excavation), and another at the point of bending at $\mathrm{C}$, which later died. However, all lateral roots above node $B$ date from 2000 or later, suggesting that at least the upper curve in the main axis between $B$ and $C$ may date from around this time.

\section{Discussion}

The novel application of SfM photogrammetry to investigate the underground structures of the investigated trees was exceptionally useful, particularly for post-hoc exploration of hypotheses to explain structural and textural characteristics which may not have been noted in the field. Though the method is not currently workable for capturing fine root architecture at the whole tree scale, there will no doubt be further improvements in technology and software allowing more detailed model construction in the future. The method certainly allows for much reduced time in the field; there is no requirement for removal and storage of roots (as in, e.g., Vennetier et al., 2015); and the automatically constructed, highly detailed model remains available for analysis with new methods, as and when they may be developed in the future. Furthermore, it is also possible to distinguish broad sediment types in the SfM model, confirming or expanding observations made in the field. 
Using a combination of SfM photogrammetry, dendrochronology, and analysis of sediment profiles around the main axis of each studied tree, it has been possible to identify a range of characteristics of this underground, living riparian wood.

Overall, the sampled trees show little difference in either their average vertical or lateral growth rates (Table 1). This reflects previous dendrochronological analysis of younger (3-m tall) trees at the two studied sites (Gurnell, 2016), where the typical growth rate across each site was around $25 \mathrm{~cm} \cdot \mathrm{y}^{-1}$ with an increasing within-site downstream trend. These annual growth rates are much smaller than observed in the larger trees investigated here, but this would be expected as trees develop from their early growth phase. Furthermore, although we did not excavate to the full depth for most trees, the investigated root systems appear to penetrate to similar depths as the roots were few and relatively small at the deepest level of observation. They also reveal a variety of interesting properties, many of which are found across the majority but not all of the sampled trees (Table 2).

Apart from the partly excavated tree N4, all tree roots were excavated to a basal gravel layer that probably represents the gravel bar surface that was originally colonized. Thus, the minimum rooting depth (i.e., that to which the main axis was excavated) extends into this basal layer. In all cases, the minimum measured rooting depth is $2.0 \mathrm{~m}$ or less, but this appears to reflect the change in elevation of the ground surface as fluvially transported sediment has accumulated around the trees rather than any common limit on the rooting depth of this species. Indeed, rooting depth of $P$. nigra to underlying gravels has been observed to exceed $3 \mathrm{~m}$ in eroding bank profiles within the lower, meandering reaches of the Tagliamento (Gurnell, personal observation). This vertical distribution is considerable in the context of the global analysis conducted by Schenk and Jackson (2002) and is important in a riparian context, as Abernethy and Rutherfurd (2001) suggested that interspecies differences in the strength of living roots of the riparian trees they investigated had less significance for bank reinforcement than interspecies differences in root distribution. Furthermore, dendrochronology indicates many young roots at depth and surprisingly few roots contemporary with the establishment of the main axis. This would suggest that even deep parts of the root systems remain active, maintaining constant turnover. It is presumed that one of the main factors driving the maintenance of the deep axes is phreatophyty, securing access to water when precipitation and storage in upper soil layers is low.

While the roots penetrate finer sediments that have accumulated above basal gravel layers, demonstrating their ability to supply some reinforcement to the entire aggraded bank profile, details of the morphology of the main axis indicate complex responses to fluvial disturbance events. The trajectories of the main axes demonstrates that all trees have been displaced in a downstream direction from their initial recruitment position to the position of the base of their trunk on the current bank top (Table 2). This horizontal displacement varies between 0.6 and $2.8 \mathrm{~m}$ and is accompanied by notable differences in subsurface morphology between the trees in the northern and southern sites. Furthermore, all trees show evidence of stem burial, the sprouting of adventitious roots and new stems from nodes on the previous main stem.

The main underground axes, particularly at the southern site, show sharp angles or steps ( 5 trees: N4, S1-S4), whereas in the northern site, one tree (N1) shows an inclined profile that subdivides into three sections at distinct breaks of slope. The remaining two trees show no distinct steps or breaks of 
slope with one having a single, straight, inclined axis (N2) and one a smooth curved axis (N3). It is also notable that the sediment profiles above the basal gravel layer show generally finer sediments and less distinct layering than those at the southern site. The complexity of the sediment and main axis profiles at the southern site suggest a history of more marked fluvial disturbances, capable of transporting and depositing coarser sediments and causing greater damage to standing trees, than at the northern site. This provides one explanation for the differences in overall structure of the roots and buried stems observed between the two sites. Furthermore, buried stems appear to make up the bulk of the subaerial structures, particularly the main axes, and in several cases support multiple aboveground stems. It was originally anticipated that the year of burial could have been pinpointed from changes in the wood vessel structure, but the clear contrasts described by Friedman et al. (2005) for Tamarix ramosissima and Salix exigua annual rings were not easily distinguishable in the $P$. nigra samples. Therefore the possibility still exists that these structures were misinterpreted roots rather than buried stems, but the great weight of other evidence supports the alternative hypothesis.

Detailed inspection of the main axis and larger roots of the four trees at the southern site and of the most southerly tree (N4) at the northern site (which is located at the narrowest channel width and steepest channel gradient sampled, where flow energy for any particular event is consequently highest), reveal that steps in the main axis profile and the highest concentrations of larger lateral roots are associated with sand and finer sediments deposited immediately above a coarser layer. This production of new lateral roots in response to stem bending corresponds to experimental results reported by Scippa et al. (2008). In contrast, the lateral roots of the remaining three trees (N1, N2, N3) are more evenly spaced along their less contorted main axes and extend into less strongly layered and generally finer sediments. Nevertheless, tree N1, which shows clear breaks of slope in its main axis, also shows major lateral roots at these breaks of slope and the presence of a coarser, gravel layer immediately below the breaks of slope. Furthermore, tree N3, shows a very complex basal root system that appears to be associated with early burial of the tree. A final important observation concerning lateral roots is the presence of root grafting on trees N4 and S3, as this undoubtedly adds further strength to the web of coarse roots within the river bank.

In addition to the above observations concerning the morphology of the main buried axis and lateral roots of $P$. nigra in the context of the bank sediment structure, dendrochronological dating of elements of the studied trees allows some process inferences to be tentatively proposed. In each case, minimum approximate dates have been established for parts of the main axis, main lateral roots, and the stem at $1.2 \mathrm{~m}$ above the ground surface; and these have been used to provide minimum approximate dates for the current main stem, the oldest parts of the root system, the steps or breaks of slope in the main axis, and the potentially associated deposition of coarser sediment layers and initiation of major lateral roots. In this context, coarser sediment layers in an otherwise upwardly fining sediment profile are interpreted as flood deposits, for which approximate dates are proposed. Table 2 suggests dates for the oldest part of the belowground wood to indicate a minimum year in which the tree started to grow from a germinated seed or piece of deposited living wood, and also the minimum for the current aboveground stem. In most cases, the aboveground stem is older than the oldest part of the belowground system, indicating some decay of the original root system. In addition, dates, morphology, 
and sediments for all but one tree suggest significant disturbance by at least two flood events. Early events are indicated variously before 1996 and 1998, with evidence from S1 suggesting that both dates may be important. Later dates are most commonly from 2000 to 2002, although dates for N3 and N4 suggest a later minimum date of 2003 or 2005 . Of course, it has already been stressed that these are all minimum dates, as many errors may have influenced these estimates, but the body of evidence points to important flood disturbance in the mid-1990s and early-2000s.

More generally, the detailed observations of underground roots and shoots of $P$. nigra presented in this paper have enormous potential relevance to the wood budget of rivers with riparian woodland dominated by the species. First, there is a very significant mass of large wood that is alive and buried in riparian sediments that has the potential to contribute to the volume of wood recruited to the river and to be transported or stored downstream. Second, this underground large wood has a highly complex form, ensuring that the root wad component of the wood budget has enormous potential to snag and thus be stored within the fluvial system and, because of its ability to sprout, to regenerate. This suggests a tightening of the wood budget by this underground wood, with relatively short distances moved before snagging, and rapid regeneration into new vegetation that in turn becomes an important factor in retaining mobile wood. Lastly, even when a tree topples and enters the river with its root wad attached, it is likely that a significant part of the underground wood may remain. Such remnant underground wood can continue to reinforce riparian sediments and, if it survives for long enough, regenerate and vegetate the riparian sediments, resulting in further tightening of the wood budget.

Although our research focused on a single species, other members of the riparian Salicaceae show similar underground traits, suggesting that other riparian willow and poplar species may offer similar underground biomass characteristics and similar relevance to the wood budget.

\section{Conclusions}

The research reported in this paper has revealed many features of the morphology of underground living wood associated with $P$. nigra, a widely occurring and often dominant riparian tree species along European rivers. The focus has been on the main underground axes and coarse lateral roots of this species and has demonstrated:

- $\quad$ Rooting depths to below the bar surface where the original tree established, with many young roots existing at depth.

- Translocation of stems in a downstream direction; steps and bends in the main belowground axis.

- $\quad$ The generation of coarse lateral roots, yielding complex underground structures within aggrading bank sediments that to some extent reflect the sedimentary structure of these aggrading sediments.

- $\quad$ The fact that much of the main subaerial axis is comprised of stems that have become buried and have then generated new shoots, including multistem patches, and adventitious roots. Grafting of these roots was also observed.

- $\quad$ All of these complex structures appear to respond to similar processes, but the resultant belowground architecture varies enormously. 
This paper has presented a first set of results from a study of the morphology and age of buried stems and roots of $P$. nigra along the Tagliamento River, Italy. The above inferences from these morphological observations are complemented and tested by Holloway et al. (2016) through a historical analysis of the processes of fluvial disturbance and vegetation growth in the vicinity of the eight studied trees.

\section{Acknowledgements}

James Holloway's research is funded by the SMART Joint Doctoral Programme (Science for Management of Rivers and their Tidal Systems), which is financed by the Erasmus Mundus Programme of the European Union. Thanks is due to the reviewers and editors whose input has greatly helped improve this manuscript.

\section{References}

Aberle, J., Järvelä, J., 2013. Flow resistance of emergent rigid and flexible floodplain vegetation. Journal of Hydraulic Research 51, 33-45.

Abernethy, B., Rutherfurd, I.D., 2001. The distribution and strength of riparian tree roots in relation to riverbank reinforcement. Hydrological Processes 15, 63-79.

Baptist, M.J., Babovic, V., Rodriguez Uthurburu, J., Keijzer, M., Uittenbogaard, R.E., Mynett, A., Verwey, A., 2007. On inducing equations for vegetation resistance. Journal of Hydraulic Research 45, $435-450$.

Bardgett, R.D., Mommer, L., De Vries, F.T., 2014. Going underground: root traits as drivers of ecosystem processes. Trends in Ecology \& Evolution 29, 692-699.

Barsoum, N., Hughes, F.M.R., 1998. Regeneration response of Black poplar to changing river levels. In: Wheater, H., Kirby, C. (Eds.) Hydrology in a Changing Environment, Wiley, Chichester, UK, pp. 397-412.

Barsoum, N., Muller, E., Skot, I., 2004. Variations in levels of clonality among Populus nigra L. stands of different ages. Evolutionary Ecology 18, 601-624.

Benda L.E., Sias J.C., 2003. A quantitative framework for evaluating the wood budget. Forest Ecology and Management 172, 1-16.

Bendix J., Stella J.C., 2013. Riparian Vegetation and the Fluvial Environment: A Biogeographic Perspective. In: John F. Shroder (Ed.) Treatise on Geomorphology, Volume 12, Academic Press, San Diego, USA, pp. 53-74.

Bertoldi, W., Gurnell, A.M., Drake, N.A., 2011. The topographic signature of vegetation development along a braided river: results of a combined analysis of airborne lidar, colour air photographs and ground measurements. Water Resources Research 47, W06525, 13 pp.

Bilby, R.E., 2003. Decomposition and nutrient dynamics of wood in streams and rivers. In: Gregory, S.V., Boyer, K., Gurnell, A.M. (Eds.) The Ecology and Management of Wood in World Rivers. American Fisheries Society, Symposium, Bethesda, Maryland, USA, pp. 135-147.

Brassard, B.W., Chen, H.Y.H., Bergeron, Y., 2009. Influence of Environmental Variability on Root Dynamics in Northern Forests. Critical Reviews in Plant Sciences 28, 179-197. 
Brunner, I., Herzog, C., Dawes, M.A., Arend, M., Sperisen, C., 2015. How tree roots respond to drought. Frontiers in Plant Science 6, Art. 547, 16 pp.

Burylo, M., Rey, F., Roumet, C., Buisson, E., Dutoit, T., 2009. Linking plant morphological traits to uprooting resistance in eroded marly lands (Southern Alps, France). Plant and Soil 324, 31-42.

Camporeale, C., Perucca, E., Ridolfi, L., Gurnell, A.M., 2013. Modelling the interactions between river morphodynamics and riparian vegetation. Reviews of Geophysics 51, 379-414.Collins, B.D., Montgomery, D.R., Fetherston, K.L., Abbe, T.B., 2012. The floodplain large-wood cycle hypothesis: A mechanism for the physical and biotic structuring of temperate forested alluvial valleys in the North Pacific coastal ecoregion. Geomorphology 139, 460-470.

Comas, L.H., Becker, S.R., Cruz, V.V., Byrne, P.F., Dierig, D.A., 2013. Root traits contributing to plant productivity under drought. Frontiers in Plant Science 4, Art. 442, 16 pp.

Corenblit, D., Tabacchi, E., Steiger, J., Gurnell, A. M., 2007. Reciprocal interactions and adjustments between fluvial landforms and vegetation dynamics in river corridors: A review of complementary approaches. Earth-Science Reviews 84, 56-86.

Corenblit, D., Steiger, J., González, E., Gurnell, A.M., Charrier, G., Darrozes, J., Dousseau, J., Julien, F., Lambs, L., Larrue, S., Roussel, E., Vautier, F., Voldoire, O., 2014. The biogeomorphological life cycle of poplars during the fluvial biogeomorphological succession: a special focus on Populus nigra L. Earth Surface Processes and Landforms 39, 546-563.

Docker, B.B., Hubble, T.C.T., 2008. Quantifying root-reinforcement of river bank soils by four Australian tree species. Geomorphology 100, 401-418.

Eckenwalder, J.E., 1996. Systematics and evolution of Populus. In: Stettler, R.F., Bradshaw, H.D., Heilman, P.E., Hinckley, T.M. (Eds.) Biology of Populus and its implications for management and conservation. Ottawa, ON, Canada: NRC Research Press, National Research Council of Canada, pp. 7-32.

Friedman, J.M., Vincent, K.R., Shafroth, P.B., 2005. Dating floodplain sediments using tree-ring response to burial. Earth Surface Processes and Landforms 30, 1077-1091.

Gale, M.R., Grigal, D.F., 1987. Vertical root distributions of northern tree species in relation to successional status. Canadian Journal of Forest Research 17, 829-834.

Guilloy-Froget, H., Muller, E., Barsoum, N., Hughes, F.M.R., 2002. Dispersal, germination, and survival of Populus nigra L. (Salicaceae) in changing hydrologic conditions. Wetlands 22, 478-488.

Gurnell, A.M., 2003. Wood storage and mobility. In: Gregory, S., Boyer, K., Gurnell, A.M. (Eds.) The Ecology and Management of Wood in World Rivers. American Fisheries Society, Symposium 37, Bethesda, Maryland, USA, pp. 75-91.

Gurnell, A.M., 2012. Fluvial Geomorphology, Wood and river landscapes. Nature Geoscience 5, 93-94.

Gurnell, A.M., 2013. Wood in fluvial systems. In: Shroder, J., Wohl, E. (Eds.), Treatise on Geomorphology Vol. 9, Fluvial Geomorphology, Academic Press, San Diego, CA, USA, pp. 163188.

Gurnell, A.M., 2016. Trees, wood and river morphodynamics, results from 15 years research on the Tagliamento River, Italy. In: Gilvear, D., Greenwood, M., Thoms, M., Wood, P. (Eds.) River Systems, Research and Management for the 21st Century, Wiley, pp. 132-155. 
Gurnell, A.M., Petts, G.E., Hannah, D.M., Smith, B.P.G., Edwards, P.J., Kollmann, J., Ward, J.V., Tockner, K., 2001. Riparian vegetation and island formation along the gravel-bed Fiume Tagliamento, Italy. Earth Surface Processes and Landforms 26, 31-62.

Gurnell A.M., Tockner, K., Edwards, P.J., Petts, G.E., 2005. Effects of deposited wood on biocomplexity of river corridors. Frontiers in Ecology and Environment 3, 377-382.

Gurnell, A.M., Blackall, T.D., Petts, G.E., 2008. Characteristics of freshly deposited sand and finer sediments along an island-braided, gravel-bed river: the roles of water, wind and trees. Geomorphology 99, 254-269.

Holloway, J.V., Rillig, M.C., Gurnell, A.M., 2016. Underground Riparian Wood: Reconstructing the Processes Influencing Buried Stem and Coarse Root Structures of Black Poplar (Populus nigra L.). Geomorphology, in press.

Jalonen, J., Järvelä, J., 2014. Estimation of drag forces caused by natural woody vegetation of different scales. Journal of Hydrodynamics 26, 608-623.

Karrenberg, S., Edwards, P.J., Kollmann, J., 2002. The life history of Salicaceae living in the active zone of floodplains. Freshwater Biology 47, 733-748.

Karrenberg, S., Kollmann, J., Edwards, P.J., Gurnell, A.M., Petts, G.E., 2003. Patterns in woody vegetation along the active zone of a near-natural Alpine river. Basic and Applied Ecology 4, $157-$ 166.

Lawson, J.R., Fryirs, K.A., Leishman, M.R., 2015. Hydrological conditions explain variation in wood density in riparian plants of south-eastern Australia. Journal of Ecology 103, 945-956.

Mahoney, J.M., Rood, S.B., 1992. Response of a hybrid poplar to water table decline in different substrates. Forest Ecology and Management 54, 141-156.

Mäkipää, R., Linkosalo, T., 2011. A Non-Destructive Field Method for Measuring Wood Density of Decaying Logs, Silva Fennica 45, research notes.

Manners, R.B., Wilcox, A.C., Kui, L., Lightbody, A.F., Stella, J.C., Sklar, L.S., 2015. When do plants modify fluvial processes? Plant-hydraulic interactions under variable flow and sediment supply rates. Journal of Geophysical Research: Earth Surface 120, 325-345.

Nguyen, P.V., Dickmann, D.I., Pregitzer, K.S., Hendrick, R., 1990. Late-season changes in allocation of starch and sugar to shoots, coarse roots, and fine roots in two hybrid poplar clones. Tree Physiology 7, 95-105.

Osterkamp, W.R., Hupp, C.R., Stoffel, M., 2012. The interactions between vegetation and erosion: new directions for research at the interface of ecology and geomorphology. Earth Surface Processes and Landforms 37, 23-36.

Pasquale, N., Perona, P., Francis, R., Burlando, P., 2012. Effects of streamflow variability on the vertical root density distribution of willow cutting experiments. Ecological Engineering 40, 167-172.

Pollen, N., Simon, A., Collison, A., 2004. Advances in assessing the mechanical and hydrologic effects of riparian vegetation on streambank stability. In: Bennett, S.J., Simon, A. (Eds.) Riparian Vegetation and Fluvial Geomorphology, AGU, Washington, D.C., USA, pp. 267-282. 
Pollen-Bankhead, N., Simon, A., 2010. Hydrologic and hydraulic effects of riparian root networks on streambank stability: Is mechanical root-reinforcement the whole story? Geomorphology 116 , 353-362.

Pregitzer, K., Friend, A.L., 1996. The structure and function of Populus root systems. In: Stettler, R.F., Bradshaw, H.D., Heilman, P.E., Hinckley, T.M. (Eds.) Biology of Populus and its implications for management and conservation. Ottawa, ON, Canada: NRC Research Press, National Research Council of Canada, pp. 331-354.

Ruiz-Villanueva, V., Díez-Herrero, A., Ballesteros, J.A., Bodoque, J.M., 2014. Potential large woody debris recruitment due to landslides, bank erosion and floods in mountain basins: a quantitative estimation approach. River Research and Applications 97, 81-97.

Ruiz-Villanueva, V., Piegay, H., Gurnell, A.M., Marston, R.A., Stoffel, M., 2016. Recent advances quantifying the large wood dynamics in river basins: new methods, remaining challenges. Reviews of Geophysics, in review.

Schenk, H.J., Jackson, R.B., 2002. The global biogeography of roots. Ecological Monographs 72, 311328.

Scherer, R., 2004. Decomposition and longevity of in-stream woody debris: a review of literature from North America. In: Scrimgeour, G.J., Eisler, G., McCulloch, B., Silins, U., Monita, M. (Eds.) Ecosystem Stewardship through Collaboration. Proceedings Forest-Land-Fish Conference II, Edmonton, Alberta, Canada, pp. 127-133.

Scippa, G.S., Trupiano, D., Rocco, M., Di lorio, A., Chiatante, D., 2008. Unravelling the response of poplar (Populus nigra) roots to mechanical stress imposed by bending. Plant Biosystems 142, 401-413.

Shepperd, W.D., Smith, F.E., 1993. The role of near-surface lateral roots in the life-cycle of aspen in the central Rocky Mountains. Forest Ecology and Management 61, 157-170.

Simon, A., Collison, A.J.C., 2002. Quantifying the mechanical and hydrologic effects of riparian vegetation on streambank stability. Earth Surface Processes and Landforms 27, 527-546.

Stotts, S., O'Neal, M., Pizzuto, J., Hupp, C., 2014. Exposed tree root analysis as a dendrogeomorphic approach to estimating bank retreat at the South river, Virginia. Geomorphology 223, 10-18.

Tabacchi, E., Planty-Tabacchi, A.M., 2003. Recent changes in riparian vegetation: Possible consequences on dead wood processing along rivers. River Research and Applications 19, 251 263.

Vennetier, M., Zanetti, C., Meriaux, P., Mary, B., 2015. Tree root architecture: new insights from a comprehensive study on dikes. Plant and Soil 387, 81-101.

Wohl, E., 2013 Floodplains and wood. Earth Science Reviews 123, 194-212.

Zanoni, L., Gurnell, A.M., Drake, N., Surian, N., 2008. Island dynamics in a braided river from an analysis of historical maps and air photographs. River Research and Applications 24, 1141-1159. 

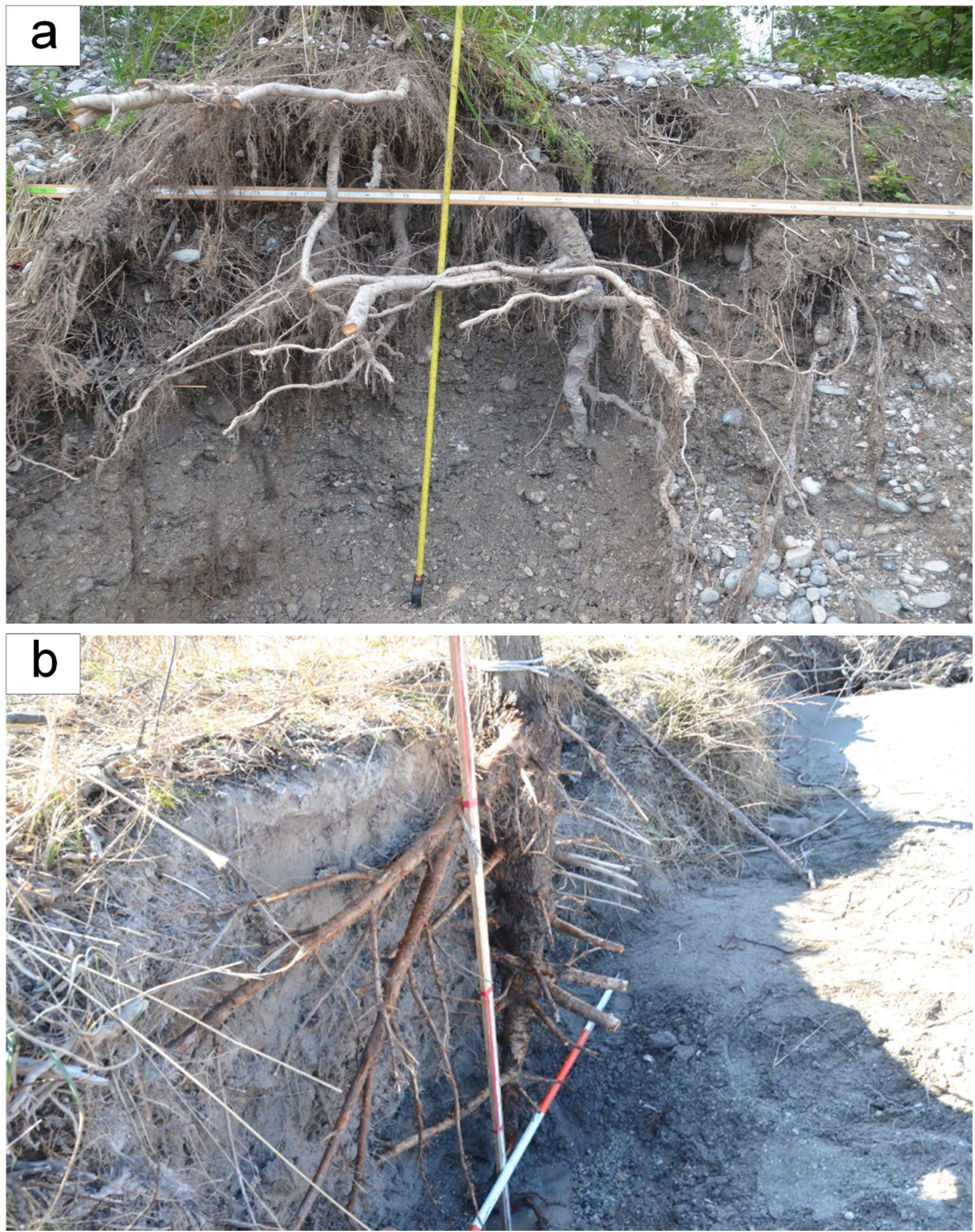

Fig. 1. (A) Tree N4, partly excavated and pruned, illustrating a typical extensive coarse root structure with many finer roots still attached but trimmed back to permit clarity in the photograph, which was taken during excavation. Image spans $2.5 \mathrm{~m}$ along the horizontal white scale (numbers are marked every 10 $\mathrm{cm}$ ). (B) Tree N2, illustrating how roots were trimmed as sediments were excavated to just beyond the main buried stem axis. Approximately $2 \mathrm{~m}$ of the vertical scale and $1.5 \mathrm{~m}$ of the horizontal scale are visible (marked segments of ranging poles are $0.5 \mathrm{~m}$ long). 

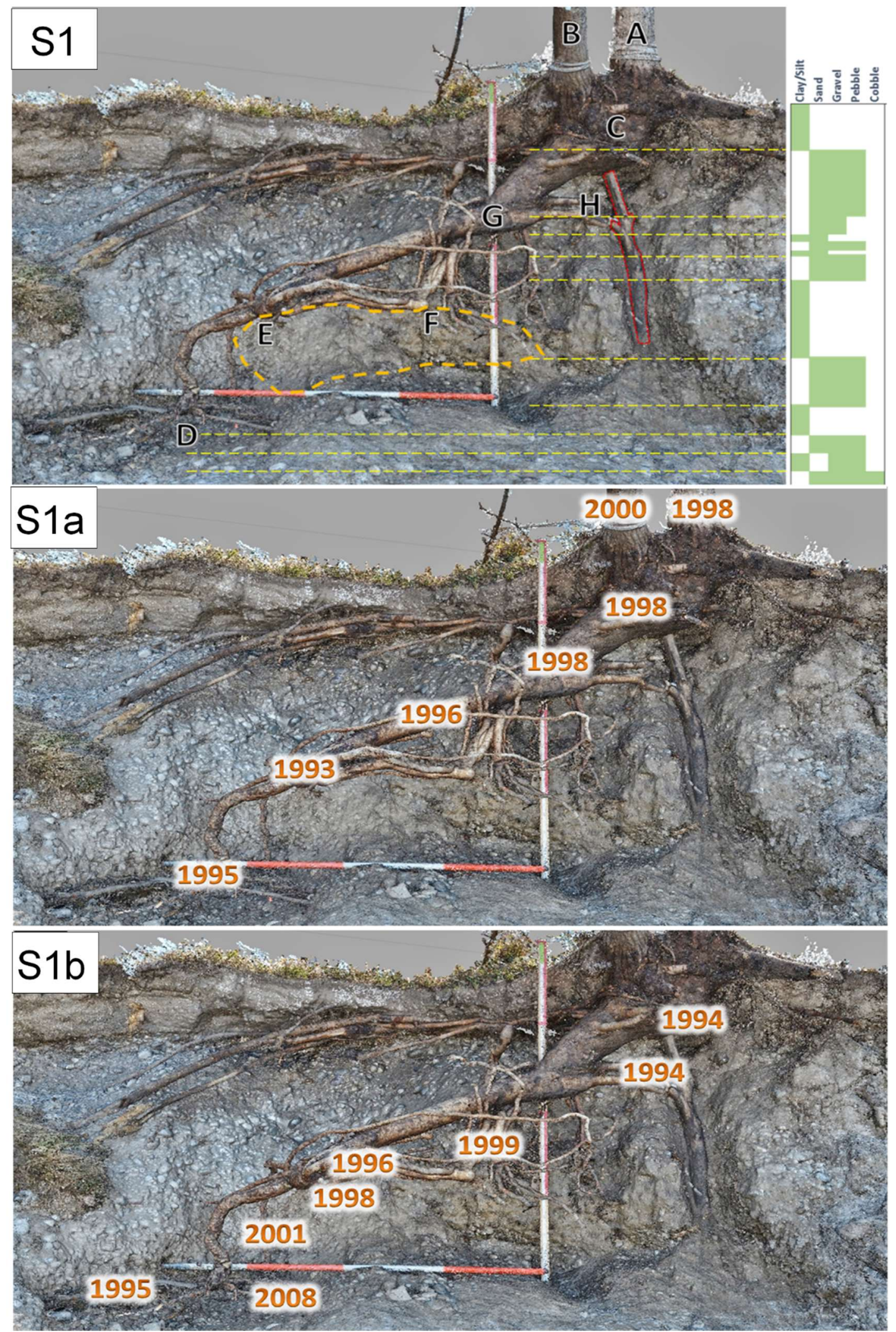

Fig. 2. Tree S1 showing (S1) key features of the root system and associated sediments (dashed golden line indicates a patch of silt and clay, red lines indicate a prop installed to support the main axis during excavation), (S1a) dates estimated for the main stems and main buried axis, (S1b) dates estimated for the major lateral roots. Marked segments of ranging poles are $0.5 \mathrm{~m}$ long here and in all subsequent figures. 

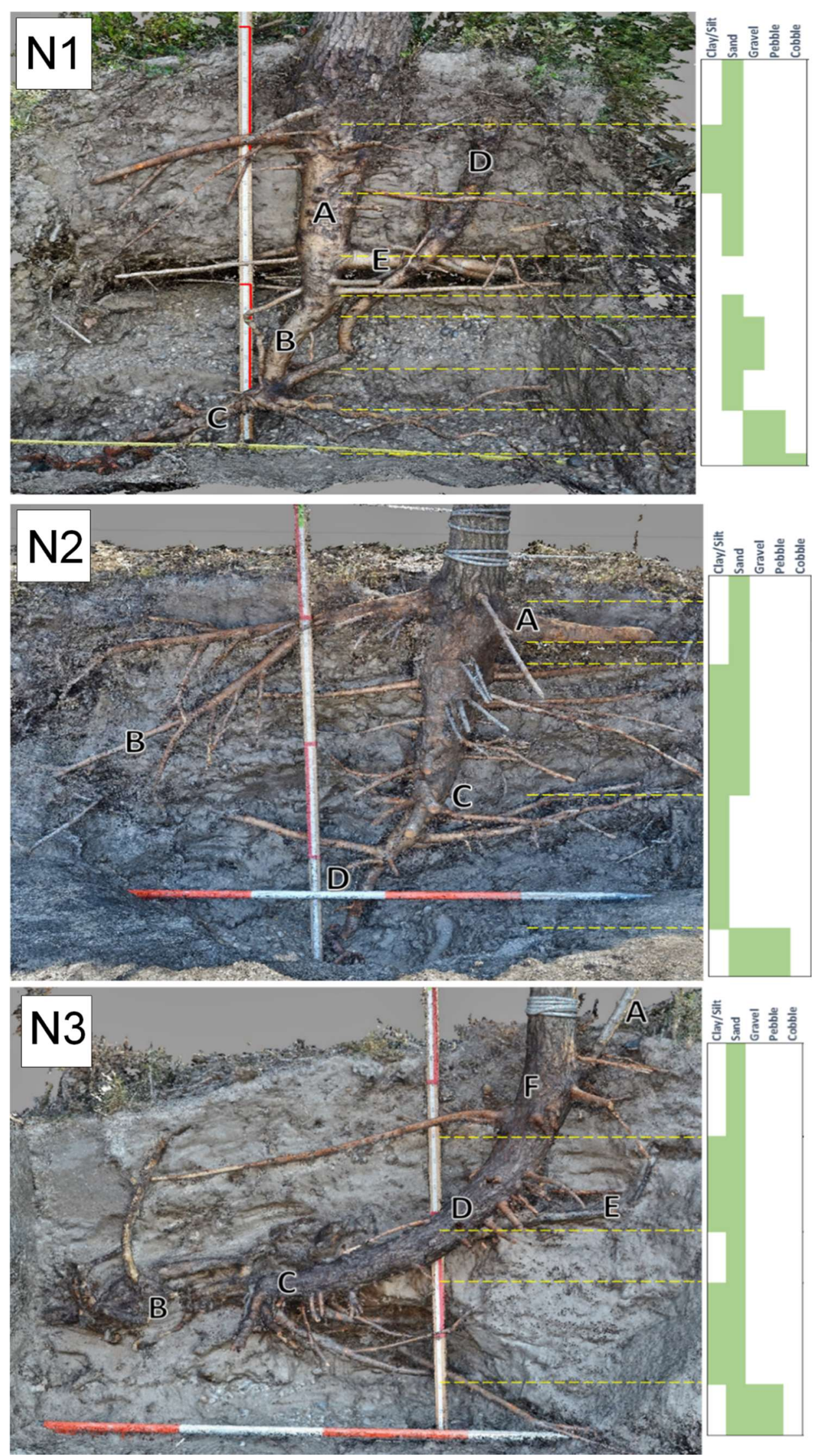

Fig. 3. Key features of the root system and associated sediments for trees N1, N2, and N3. 

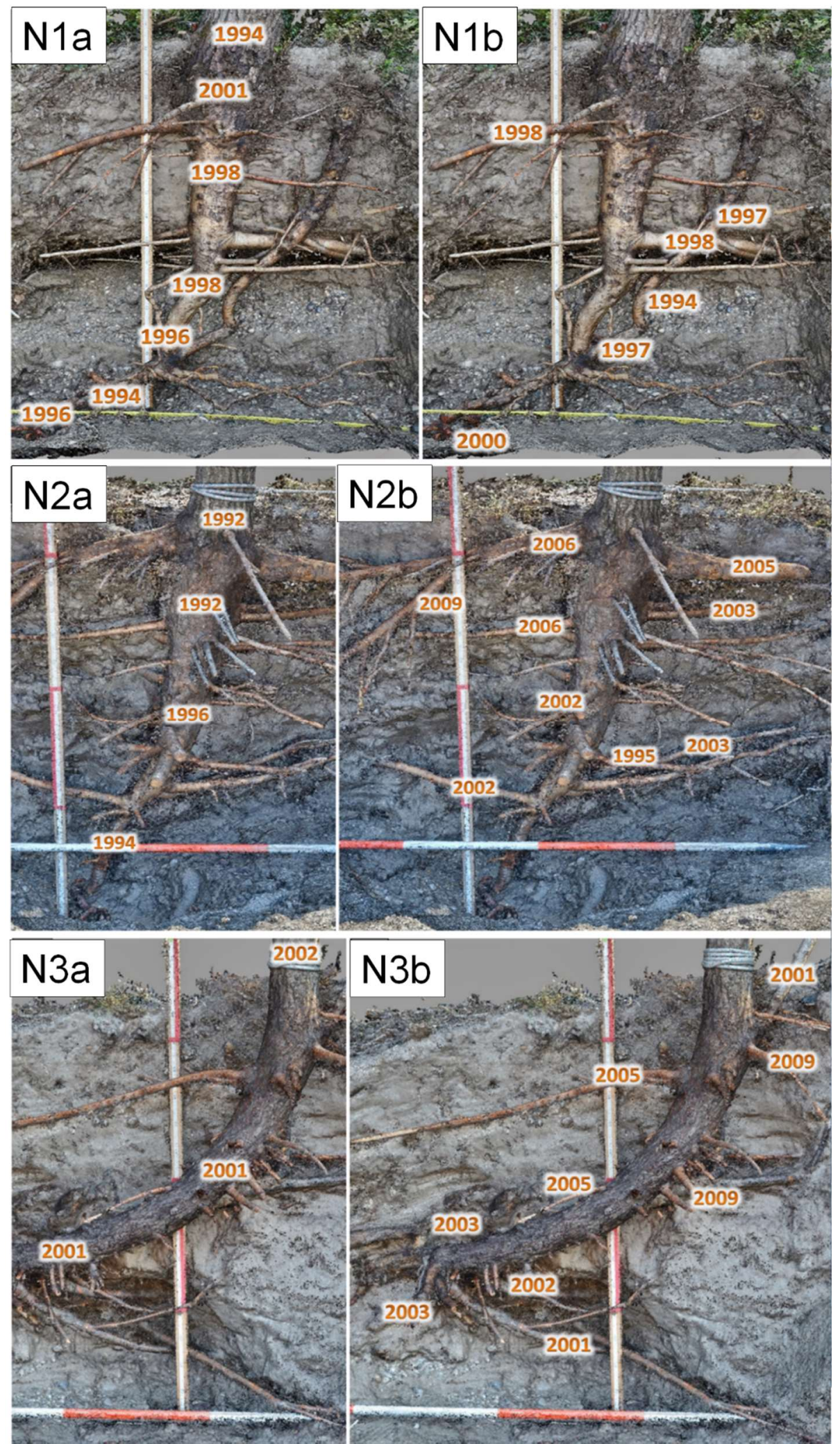

Fig. 4. Estimates of latest possible dates of origin of the main stem and main buried axis (A), and major lateral roots (B) for trees N1, N2, N3. 

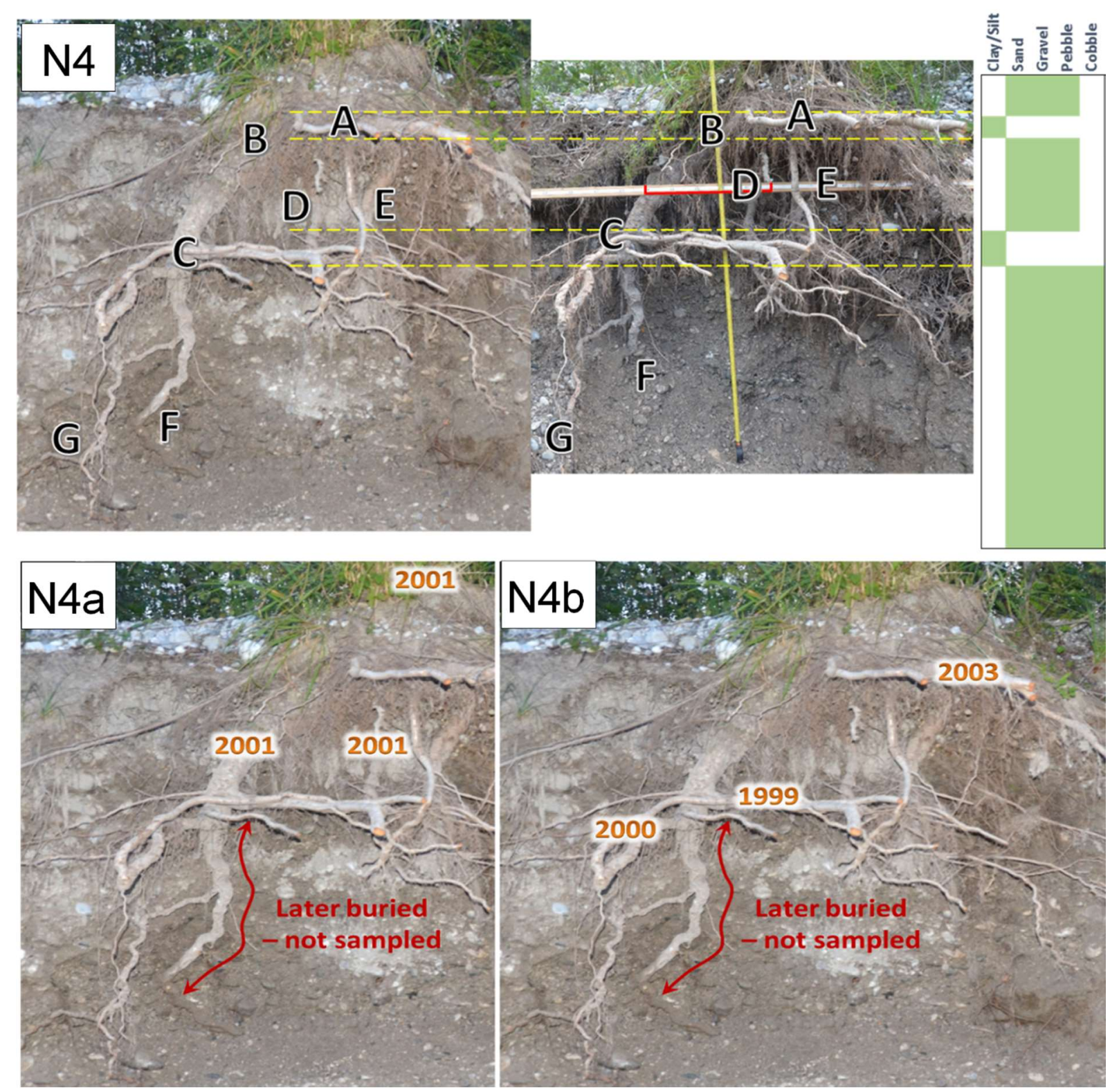

Fig. 5. (N4) Two images of the root system of tree N4 at different stages of (incomplete) excavation, with key features labelled and main sedimentary strata identified; estimates of latest possible dates of origin of (N4a) different parts of the main axis and (N4b) supporting vertical root and lateral roots. 

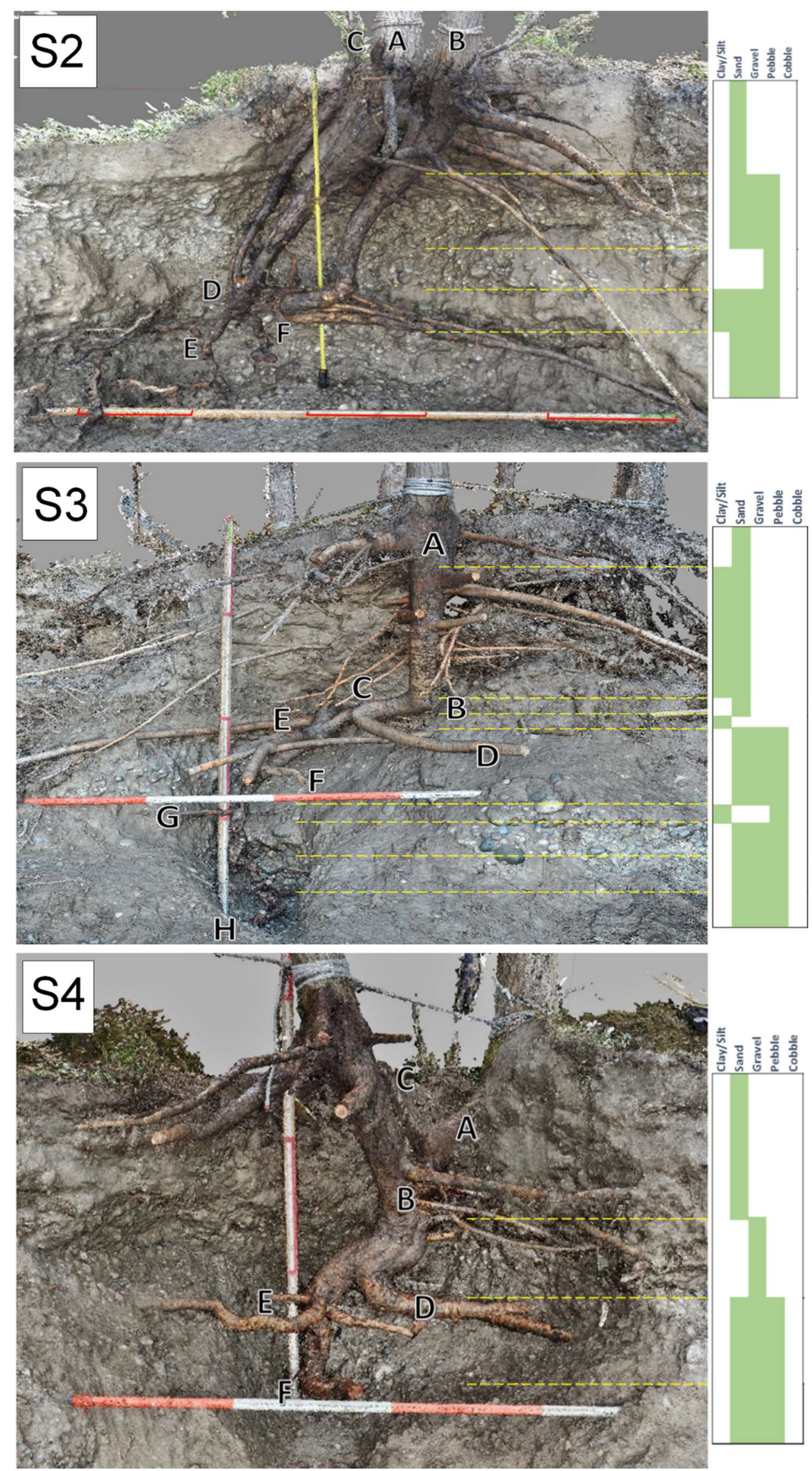

Fig. 6. Key features of the root system and associated sediments of trees S2, S3, and S4. 

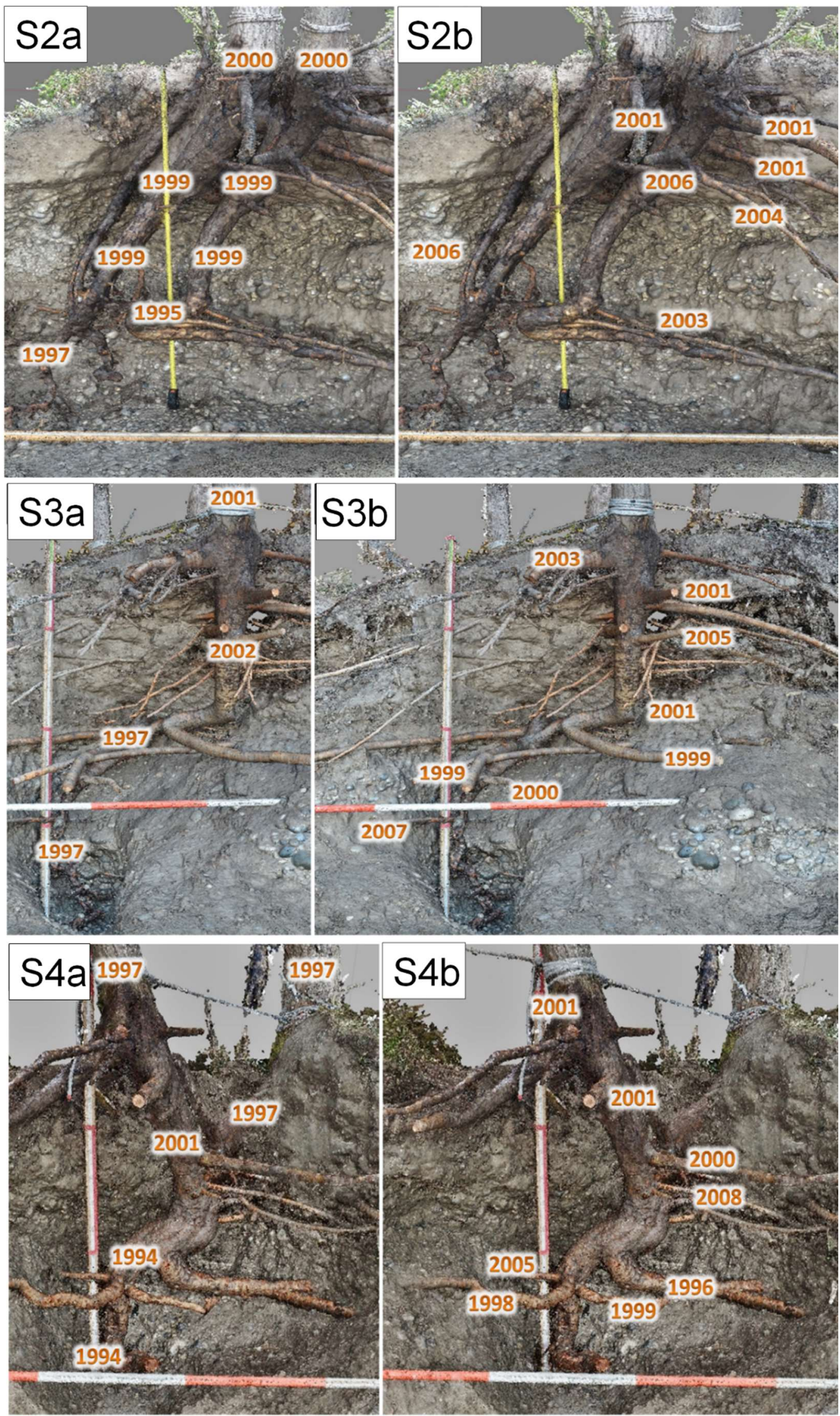

Fig. 7. Estimates of latest possible dates of origin of the main stem(s) and main buried axis (A), and major lateral roots (B) for (top) tree S2, (middle) tree S3, (bottom) tree S4. 


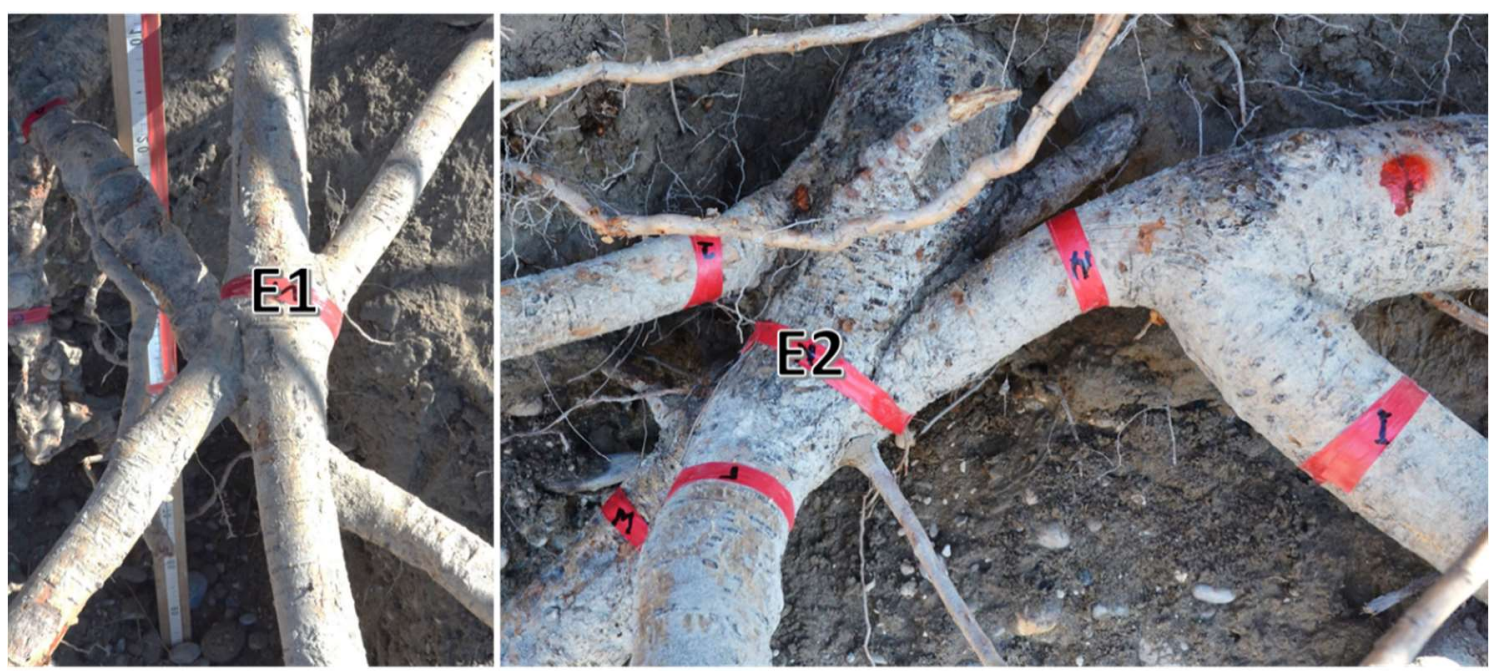

Fig. 8. Details of two grafts (E1, E2) between roots of tree S3 and other stems in the cluster around point E (Fig. 6, S3).

Table 1

Measured properties of the aerial stems of the eight studied trees (where two stems were present, measurements relate to the larger stem)

\begin{tabular}{|c|c|c|c|c|c|c|c|c|c|}
\hline Tree & $\begin{array}{c}\text { Year } \\
\text { surveyed }\end{array}$ & $\begin{array}{l}\text { Latitude } \\
\text { (degrees) }\end{array}$ & $\begin{array}{l}\text { Longitude } \\
\text { (degrees) }\end{array}$ & $\begin{array}{c}\text { Number } \\
\text { of } \\
\text { stems }\end{array}$ & $\begin{array}{c}\text { Stem age } \\
\text { at } 1.2 \mathrm{~m} \\
\text { (years) }\end{array}$ & $\begin{array}{l}\text { Diameter } \\
\text { at } 1.2 \mathrm{~m} \\
(\mathrm{~cm})\end{array}$ & $\begin{array}{c}\text { Stem } \\
\text { length (m } \\
\text { to nearest } \\
0.25 \mathrm{~m})\end{array}$ & $\begin{array}{l}\text { Radial } \\
\text { growth } \\
\text { rate } \\
\left(\mathrm{mm} \cdot \mathrm{y}^{-1}\right)\end{array}$ & $\begin{array}{c}\text { Vertical } \\
\text { growth } \\
\text { rate } \\
\left(\mathrm{m} . \mathrm{y}^{-1}\right)\end{array}$ \\
\hline N1 & 2014 & 46.23794 & 13.04350 & 1 & 20 & 23 & 17.00 & 5.7 & 0.9 \\
\hline N2 & 2015 & 46.22428 & 13.03729 & 1 & 19 & 13 & 13.00 & 3.4 & 0.7 \\
\hline N3 & 2015 & 46.20108 & 12.97370 & 1 & 12 & 12 & 13.25 & 4.8 & 1.1 \\
\hline N4 & 2014 & 46.20632 & 12.98691 & 1 & 13 & 15 & 13.00 & 5.8 & 1.0 \\
\hline s1 & 2015 & 45.93784 & 12.90416 & 2 & 16 & 15 & 11.25 & 4.7 & 0.7 \\
\hline S2 & 2014 & 45.93609 & 12.90407 & 2 (alive) & 14 & 16 & 11.00 & 5.7 & 0.8 \\
\hline S3 & 2015 & 45.93468 & 12.90443 & 1 & 13 & 15 & 12.50 & 5.6 & 1.0 \\
\hline S4 & 2015 & 45.93320 & 12.90451 & 2 & 17 & 15 & 16.75 & 4.4 & 1.0 \\
\hline Average & & & & & 15.5 & 16.1 & 13.8 & 5.3 & 0.9 \\
\hline
\end{tabular}


Table 2

Summary of observed features of tree coarse root morphology, age, and associated sediments

\begin{tabular}{|c|c|c|c|c|c|c|c|c|}
\hline Tree & N1 & N2 & N3 & N4 & S1 & S2 & S3 & S4 \\
\hline $\begin{array}{l}\text { Stem at } 1.2 \mathrm{~m} \text { dates to } \\
\text { (before) }\end{array}$ & 1994 & 1996 & 2003 & 2001 & 1999 & 2000 & 2002 & 1998 \\
\hline $\begin{array}{l}\text { Oldest belowground } \\
\text { age (before) }\end{array}$ & 1994 & 1992 & 2001 & 1999 & 1993 & 1995 & 1997 & 1994 \\
\hline $\begin{array}{l}\text { Estimated flood } 1 \\
\text { (before) }\end{array}$ & 1996 & $\begin{array}{l}\text { early } \\
1990 \text { s }\end{array}$ & 2005 & $\begin{array}{l}2000- \\
2001\end{array}$ & 1993 & $\begin{array}{l}\text { mid } \\
1990 s\end{array}$ & 1999 & 1996 \\
\hline $\begin{array}{l}\text { Estimated flood } 2 \\
\text { (before) }\end{array}$ & 1998 & 2002 & & 2003 & 1996 & $\begin{array}{l}\text { late } \\
\text { 1990s }\end{array}$ & $\begin{array}{l}2000- \\
2001\end{array}$ & $2000 ?$ \\
\hline $\begin{array}{l}\text { Estimated flood } 3 \\
\text { (before) }\end{array}$ & & & & & $\begin{array}{l}\text { late } \\
\text { 1990s }\end{array}$ & & & \\
\hline $\begin{array}{l}\text { Minimum rooting depth } \\
\text { (m) }\end{array}$ & 1.8 & 1.8 & 1.8 & $1.4 ?$ & 2.0 & 1.9 & 1.9 & 1.3 \\
\hline $\begin{array}{l}\text { Downstream } \\
\text { displacement of main } \\
\text { axis }(m)\end{array}$ & 1.1 & 0.6 & 1.4 & $1.0 ?$ & 2.8 & 0.9 & 0.9 & 0.3 \\
\hline Shape of main axis & $\begin{array}{c}\text { 3- } \\
\text { section } \\
\text { inclined }\end{array}$ & inclined & curved & stepped & $\begin{array}{l}\text { mainly } \\
\text { inclined, } \\
1 \text {-step }\end{array}$ & stepped & stepped & stepped \\
\hline $\begin{array}{l}\text { Step / section } \\
\text { boundaries in main } \\
\text { axis above junction } \\
\text { with coarser sediment } \\
\text { layer }\end{array}$ & yes & $\begin{array}{l}\text { no } \\
\text { steps }\end{array}$ & $\begin{array}{l}\text { no } \\
\text { steps }\end{array}$ & yes & yes & yes & yes & yes \\
\hline $\begin{array}{l}\text { More / larger lateral } \\
\text { roots present } \\
\text { immediately above } \\
\text { junctions with coarser } \\
\text { sediment layers }\end{array}$ & yes & $\begin{array}{l}\text { no } \\
\text { steps }\end{array}$ & $\begin{array}{l}\text { no } \\
\text { steps }\end{array}$ & yes & yes & yes & yes & yes \\
\hline Roots grafted & no & no & no & yes & no & no & yes & no \\
\hline
\end{tabular}

